\title{
Implementing a Life Cycle Approach through Establishment of a Multipurpose Behavior Therapy Room in PGIMER, Chandigarh for Enhancing the Fitness Level of Women
}

\author{
${ }^{1}$ Ruchi Sharma, ${ }^{2}$ Lakhbir Kaur Dhaliwal, ${ }^{3}$ Vanita Suri, ${ }^{4}$ Purnima Kaushal, ${ }^{5}$ Neha Singhal \\ ${ }^{6}$ Avinash Kaur Rana, ${ }^{7}$ Amarjeet Singh
}

\begin{abstract}
Introduction: In India, women in their natural role as mothers, sisters, wives, and daughters have been accepted as the principal providers of good health to their families and indirectly to the community. Yet, when it comes to their own health, it receives low priority. Health and fitness of women is compromised by gynecological morbidities that they consider as 'normal' and part of their destiny. For example, in dysmenorrhea, girls remain grounded for 3 to 4 days. Uterine prolapse and urinary leakage compromise quality of women's life. Many of these problems of women can be resolved by nonmedicinal interventions. Therefore, every woman should have the opportunity to learn about the self-care of problems they experience. However, the doctors in the outpatient departments, particularly Obstetrics and Gynecology (OPG-OPD) are usually overworked to explain this to patients.
\end{abstract}

Objective: To document the feasibility and impact of instituting a health promotion orientation package in OPG-OPD in an apex hospital of North India.

Materials and methods: A health promotion orientation package of services was instituted in OPG-OPDs in an apex hospital of north India through a multipurpose behavior therapy (MPBT) room in December 2012. After referral from main OPD, patients of pregnancy, infertility, prolapse, urinary incontinence (UI), menopause, and dysmenorrhea were advised nonmedicinal interventions, such as dietary modifications, lifestyle changes, and simple exercises/yoga. Unlike main OPG-OPD, here patients were attended along with their husbands and other family members. Here patients shared their queries without hesitation. Patients were also given booklets (available in Hindi, English, Punjabi) and other IEC material on related problems free of charge.

\footnotetext{
1,5Senior Research Fellow, ${ }^{2,3,7}$ Professor, ${ }^{4}$ Research Associate ${ }^{6}$ Lecturer

1,4,5,7 School of Public Health, Postgraduate Institute of Medical Education and Research, Chandigarh, India

${ }^{2,3}$ Department of Obstetrics and Gynaecology, Postgraduate Institute of Medical Education and Research, Chandigarh, India

${ }^{6}$ National Institute of Nursing Education, Postgraduate Institute of Medical Education and Research, Chandigarh, India
}

Corresponding Author: Ruchi Sharma, Senior Research Fellow, School of Public Health, Postgraduate Institute of Medical Education and Research, Chandigarh, India, Phone: +919463049444 e-mail: ruchi_sharma158@yahoo.com
Results: Favorable results of nonmedicinal interventions were reported. Around 5000 patients were successfully managed through this approach in three years.

Out of 100 menopausal patients referred to the MPBT room, 64 were successfully followed up. Among $759 \mathrm{UI}$ and prolapse of pelvic organs patients visiting the room, $66 \%$ reported total relief in symptoms and $26 \%$ patients reported partial relief after following behavior therapy instructions.

Around 3000 antenatal care patients counselled reported relief in symptoms and satisfaction with the quality of counselling. They were also happy that they are being listened to patiently.

Patients of polycystic ovarian disease, infertility, and dysmenorrhoea were also advised simple exercises, dietary changes, and lifestyle modifications.

Conclusion: Establishing a counseling room/MPBT room in hospital, OPDs has a potential to help women cope better with the issues related to their health. Replication of this model in other medical colleges will also help in reducing the load on doctor while simultaneously enhancing patient satisfaction.

Keywords: Counselling, Demedicalization, Health promotion, Women's health and fitness.

How to cite this article: Sharma R, Dhaliwal LK, Suri V, Kaushal P, Singhal N, Rana AK, Singh AJ. Implementing a Life Cycle Approach through Establishment of a Multipurpose Behavior Therapy Room in PGIMER, Chandigarh for Enhancing the Fitness Level of Women. J Postgrad Med Edu Res 2017;51(3):115-122.

Source of support: This project was fully funded by Department of Bio-Technology, Government of India.

\section{Conflict of interest: None}

\section{INTRODUCTION}

When we talk about women's health, the focus of health care providers has continued to be on maternal mortality related targets even in millenium development goalsrelated strategies. Now, in post 2015 scenario, we should strive to improve the quality of lives of women by addressing routine gynecological problems, many of which can be managed through lifestyle changes and self-care supported by behavior therapy (BT). In our country, women in their natural role as mothers, sisters, wives, and daughters have been accepted as the principal providers of good health to their families and indirectly to the community. Yet, when it comes to her own health, it receives a low priority. Like, 
Pelvic organ prolapse and UI compromise quality of life of women. ${ }^{1-4}$ Ironically, women are expected to remain silent and keep on tolerating their sexual and reproductive health problems. Health and fitness of women is compromised by gynecological morbidities that they consider as 'normal' and part of their destiny. ${ }^{5-7}$ For example, in dysmenorrhea, girls remain grounded for 3 to 4 days. ${ }^{8,9}$ Uterine prolapse and urinary leakage also compromise quality of their life as their fitness level is affected. Many of these problems of women can be resolved by nonmedicinal interventions, e.g., appropriate BT, exercises, health education, counselling, and guidance. ${ }^{10-14,6,7,15,16}$ However, the doctors in the OPDs, (particularly OPG-OPD) are usually overworked to explain this to patients. Therefore, every woman should have the opportunity to learn about the self-care of problems she is experiencing. ${ }^{5}$

In this context, this article shares the experiences of our efforts to enhance the fitness level of women reporting to OPG-OPDs. An MPBT room was set up in OPGOPD of Postgraduate Institute of Medical Education and Research, Chandigarh in December 2012. A variety of health and fitness problem of women of all age groups (ranging from dysmenorrhea in girls to menopause related issues in women) were addressed here. The catchment population of PGIMER is mainly from North India. Patients from urban, peri-urban, and rural areas from four states of North India, i.e., Punjab, Haryana, Himachal Pradesh, and Jammu and Kashmir come to the institute for treatment. It is expected to function as a referral institute. However, the doctors in the OPDs, (particularly OPG-OPD) are usually overburdened due to the large number of patients they have to attend. Therefore, quality of care provided in hospitals is compromised due to the overcrowded situation prevailing there. Much of the time of specialist doctors is wasted in attending to the routine problems of patients since no screening is done to ensure that at risk cases get more attention. Given the prevailing scenario of referral system in India, much of the time of specialist doctor is wasted in attending to the routine problems/queries of patients.

Consequently, they have no time or patience to explain self-care interventions to the patients. So, more or less, a lip service is given in OPDs during patient management to conservative modalities. The time of the doctors is also wasted when the dissatisfied patients keep pestering them with unnecessary queries (because they were not explained about their problem at the first instance). In fact, a lot of consultation time of doctors can be saved if someone else deals with imparting such an advice to the patients. Moreover, it is often seen that not much attention is given in the hospitals on emphasizing upon the patients and their relatives about the importance/effectiveness of the conservative management of various maladies.
The concept of salutogenesis needs to be popularized. ${ }^{17}$ Setting up a multipurpose behavior therapy (MPBT) room in OBG-OPD was an effective step in this direction. This research project was initiated after success of previous DBT sponsored project on BT for UI where $60 \%$ patients reported relief in symptoms after kegel exercises, bladder training, and lifestyle modifications. ${ }^{10-12}$

\section{OBJECTIVE}

To document the feasibility and impact of instituting a health promotion orientation package in OBG-OPD in an apex hospital of North India.

\section{MATERIALS AND METHODS}

A health promotion orientation package of services was instituted in OBG-OPD in an apex hospital of north India-PGIMER, Chandigarh through an MPBT room in December 2012 with total project grant of rupees 28,44,400 from Department of Biotechnology, government of India. It was joint initiative of OBG and community medicine department of PGIMER, Chandigarh. Before starting the room, information was collected on: Patient load, cure rate, relief obtained, satisfaction with therapy, money spent, compliance rate average cost of UI therapy (conventional), and man days lost for UI therapy (conventional) (patient; nurse, doctors).

Then a meeting was held in OBG department with the faculty and senior residents. A room was arranged for establishing the MPBT room (room number 2060, new OPD). A research associate and a senior research fellow coordinated the work of the MPBT room. Standard operating procedures were developed for intervention in different morbidities. Necessary furniture, etc. was procured. The information education and communication (IEC) material was devised and displayed inside and outside MPBT room. Posters for publicity of MPBT room were pasted in many places in OBG-OPD. Referral of uncomplicated patients from OBG-OPD to MPBT room was requested.

After initial checkup in the main OPD, cases of pregnancy, infertility, prolapse, UI, menopause, and dysmenorrhea were referred to the MPBT room. They were advised nonmedicinal interventions, such as dietary modifications, lifestyle changes and simple exercises/yoga. The approach to deal with patients in routine OPG-OPDs was different from the one adopted in MPBT room (Table 1). The patients were first examined by doctors in OBGOPD. Uncomplicated cases of above mentioned problems were then referred to MPBT room for counselling. The complicated cases which required other gynecological interventions were managed in the main OPD.

Apart from exercises, simple changes in diet and simple meditation techniques were also demonstrated 
Table 1: Problem and treatment approaches in MPBT room

\begin{tabular}{lllll}
\hline Problem & & \multicolumn{4}{c}{ Treatment approaches in MPBT room } & \\
\hline Urinary incontinence & Kegel exercise & Bladder training & Diet modifications & Booklets for self-care \\
Prolapse of pelvic organs & Kegel exercise & Lifestyle modification & Diet modifications & Booklets for self-care \\
Menopausal symptoms & Detailed counselling & Lifestyle modification & Diet modifications & Booklets for self-care \\
Pregnancy & Detailed counselling & Lifestyle modification & Diet modifications & Booklets for self-care \\
Infertility/PCOD & Detailed counselling & Lifestyle modification-Weight reduction & Diet modifications & Booklets for self-care \\
Dysmenorrhea & Exercise & Lifestyle modification & Diet modifications & Booklets for self-care \\
\hline
\end{tabular}

PCOD: Polycystic ovarian disease

in the MPBT room. The patient-centered approach was grounded on the idea that the patient herself is the best resource to solving her problems. The research team took on the responsibility of providing an open and comfortable atmosphere to the patient which allowed her to express her problems freely. This type of counselling was heavily focused on the patient's development as a person and her self-perceptions and power to change. The approach in MPBT room was that when the women come up with her health concerns, it is a good opportunity to review her lifestyle.

Unlike OBG-OPDs, here patients were attended along with their husbands and other family members. Male or female escorts of the patients were also invited for counselling. Here, patients and their family members shared their queries without hesitation. Patients were also given booklets (available in Hindi, English, Punjabi) 6,7,9,15,16,18-21 and other IEC material on related problems. Laptop-based IEC material was also given. The IEC material flip charts, banners are also displayed in the room. Demonstrations of requisite exercises were held. Patients were counselled here at leisurely pace and their queries are duly attended to. The benefits of the room were also popularized through print media, TV, radio, and social networking sites like face book so that more females come up with their problems. Enrolled patients were contacted telephonically for follow-up. They were motivated to follow the instructions given to them. Subjective responses of the patients were noted regarding the benefits of counselling received as perceived by them.

\section{RESULTS}

Favorable results of nonmedicinal interventions were reported. Approximately 5000 patients were successfully managed through this approach. The demedicalization philosophy inherent in the use of BT/counselling in this room helped in empowering the women to control their reproductive health. This approach provided relief to them without resorting to any medication. This approach also improved the socio-medical environment of 'pill for every ill' kind of medicalized life of citizens. It also helped in avoiding unnecessary consultation with doctors for issues which could be sorted out by the MPBT team (Table 2).

On an average, 15 to 20 patients visit the OBG-OPD of PGIMER for the menopause related problems every month (220-240 patients OPD every year). A total of 130 menopause patients were enrolled in MPBT room. Out of these, 73 patients were followed up successfully. Among them, 47 patients (64.38\%) reported complete relief in symptoms after following instructions whereas $22(30.14 \%)$ patients reported partial relief after the counselling. Overall, $53(40.76 \%)$ patients attained natural menopause, $57(43.84 \%)$ are perimenopausal, $24(18.47 \%)$ had undergone hysterectomy and $2(1.54 \%)$ had premature menopause. The profile of the patients is shown in Table 3.

Indication for hysterectomy/Oophorectomy indicates that cysts/fibroids was the most prominent cause for the hysterectomy while heavy bleeding followed by other causes like malignancy/swelling in uterus in women with surgical/induced menopause. Among them, hormone

Table 2: Difference in approach adopted in MPBT room and routine obstetrics and gynaecology OPD

\begin{tabular}{lll}
\hline Parameters & Approach adopted in OPD & Approach in MPBT room \\
\hline Symptoms tackling approach & Medicine/Surgery & $\begin{array}{l}\text { No medicines, counselling, } \\
\text { lifestyle modification and diet } \\
\text { recommendations }\end{array}$ \\
Time devoted per patient & & $25-35$ minutes \\
Medication & $5-7$ minutes (maximum) & No \\
Patient listening & Yes & Active \\
Counselling & Less & Yes \\
Escorted by husband/Family member allowed in OPD & No/minimal & Yes \\
Booklets given & No & Yes \\
Videos/CD given & No & Yes \\
Display/Other information, education, communication material & No & No \\
Follow up through WhatsApp/SMS/Reminder calls & No & Yes \\
\hline
\end{tabular}


Table 3: Profile of menopause patients counselled in MPBT room

\begin{tabular}{lll}
\hline Demographic parameter & Mean & Range \\
\hline Age of the patients & 48.36 years & $42-54$ \\
Age at menarche & 14.25 years & $12-16$ \\
Number of pregnancies & 3 & $2-6$ \\
Number of children (parity) & 2 & $2-4$ \\
Age at first child birth & 22.98 years & $19-23$ \\
Age at last child birth & 27.32 years & $23-35$ \\
Age at menopause & 44.59 years & $44-52$ \\
Age at hysterectomy (for $\mathrm{n}=20$ ) & 38.29 years & $35-41$ \\
\hline
\end{tabular}

replacement therapy (HRT) was advised to 5 patients. All of them had hot flushes.

Table 4 explains the symptoms reported in post, peri and surgical menopausal women. Hot flushes followed by heart discomfort were the most common symptoms reported by the women. Joint pains, moods swings, and irritability were the other symptoms reported in both post and perimenopausal patients. Three patients who had natural menopause were given HRT. Out of total sample, only one perimenopausal patient was given MHT (menopausal hormone therapy).

This BT approach enabled menopausal patients to enjoy life with positive attitude and independence.

In MPBT room, $759 \mathrm{UI}$ and pelvic organ prolapse (POP) patients were enrolled. Many (434) of the patients belonged to age group 30 to 50 years of age followed by age group of 50 to 70 years (325). A total of $200(26 \%)$ reported complete and $500(66 \%)$ had partial relief in their symptoms with kegel exercises and lifestyle modifications (Table 5).

As majority of patients (571) had problem of constipation, it can be one of the exaggerating factors for problem of UI and POP.

Because of the universal fear among people of surgery of any kind, the nonsurgical relief obtained through BT was welcomed by UI and prolapse cases. This approach also saved money (likely to be spent on-medical consultation, travel to hospital, investigation, medicine, operation if advised, workdays lost) for the UI cases and prolapse as BT does not involve any expenditure. Disruption of life due to BT was negligible as compared to surgical/medical therapy. Patients' subjective response itself reflected that how these females were benefited from the counselling/lifestyle modifications given in the MPBT room.

MPBT approach has provided treatment to suffering patients, without any need to undergo surgery. This has proved to be an empowerment mechanism for women.

Similarly, during pregnancy and childbirth, a woman needs proper guidance and support. However, with the rapid pace of industrialization and urbanization in today's society, the joint family system has broken down.
Table 4: Common symptoms reported by the counselled patients

\begin{tabular}{llll}
\hline & $\begin{array}{l}\text { Post } \\
\text { menopause }\end{array}$ & $\begin{array}{l}\text { Perimenopause } \\
n=36\end{array}$ & $\begin{array}{l}\text { Surgical } \\
n=18\end{array}$ \\
Symptoms & $n=39$ & 33 & 14 \\
\hline Hot flashes & 36 & 9 & 6 \\
Sleep disturbance & 6 & 12 & 6 \\
Heart discomfort & 18 & 9 & 6 \\
Joint pains & 11 & 10 & 4 \\
Mood swings & 12 & 14 & 4 \\
Irritability & 10 & 16 & 2 \\
Anxiety & 8 & 10 & 2 \\
Mental/Physical & 5 & & \\
exhaustion & & 4 & 4 \\
Sexual problem & 4 & 2 & 1 \\
Bladder problems & 4 & 10 & 3 \\
Dryness in vagina & 5 & & \\
\hline
\end{tabular}

Around 3000 antenatal care (ANC) patients counselled in MPBT room have reported relief in symptoms and satisfaction with the quality of counselling. Women were also happy that they are being listened to patiently. Study indicates that pregnant patients faced a variety of minor symptoms ranging from weakness, swelling in the face, hands, legs, and feet. Training provided in MPBT room improved the percentage of patients who took correct actions to overcome the symptoms of minor problems which mothers faced in pregnancy.

Postnatal care (PNC) was also taught in the room. Breast care, care of new born, care of wound were

Table 5: Profile of UI and POP patients

\begin{tabular}{ll}
\hline Age distribution & \\
Below 50 & 434 \\
Above 50 & 325 \\
Marital status & \\
Married & 749 \\
Unmarried & 3 \\
Widow & 4 \\
Divorcee & 3 \\
Number of children (parity) & \\
$0-2$ & 457 \\
$3-5$ & 282 \\
6-8 & 20 \\
Patients with problem of constipation & \\
Yes & 571 \\
No & 188 \\
Obstetric and gynecological history of patients & \\
Hysterectomy & 77 \\
Irregular periods & 24 \\
Lactating amenorrhea & 12 \\
Menopause & 89 \\
a) Normal & 38 \\
b) Perimenopause & 48 \\
c) Postmenopause & 123 \\
NA & 348 \\
\hline Total & 759 \\
\hline
\end{tabular}


explained in detail. Due focus was given to exercises during ANC-PNC period. This helped in enhancing their fitness level, ease in delivery, and recovery after childbirth.

Patients of polycystic ovarian disease (PCOD) were also counselled and advised weight loosing measures, exercises, yoga, and lifestyle modifications. Concept of healthy diet and healthy lifestyle was explained to them. They were guided on importance of weight reduction in treatment of PCOD. A total of 200 patients were successfully counselled on weight reduction measures. Majority $(\sim 150)$ had shown good compliance to given instructions. Therefore, they reported weight loss and regulation of menstruation with diet changes and regular exercise.

Infertile couples were also advised simple exercises, dietary changes, and lifestyle modifications in this room. Unlike OBG-OPDs, couples were counselled together in MPBT room. Thus, they understood their problem better and expressed their concerns without any hesitation. A total of 150 patients were counselled patiently in this room. Out of them, 20 patients conceived successfully. For those who could not conceive despite treatment, adoption services were linked up.

In MPBT room, dysmenorrhea patients were advised simple exercises, dietary modifications and hot water fomentation. A total of 25 dysmenorrhea patients were counselled in this room. Majority $(\sim 17)$ reported relief in pain and stopped use of pain killers for dysmenorrhea.

\section{DISCUSSION}

Patient satisfaction is a "natural" indicator for the right to health. It is important for doctors to have a conversation with the patients. All women approaching the OPG-OPDs should have an opportunity to learn about the conservative management of the problems they are experiencing. However, patient listening is very less or minimal in regular OBG-OPDs due to time constraints. The health promotion principle demands that a health culture needs to be developed among the general public that many of their medical problems can be tackled even without any medicine/tablet/capsule/injection or surgery. ${ }^{5,17}$ Such cases need to be weaned off their habit/ dependence on drugs or medicinal cure. Human body's power of self-healing needs to be strongly emphasized. There is an inherent element of demedicalization in this MPBT project. This counselling/BT approach reduced the dependence of patients on doctors/medicines. Need of direct consultation with doctors was also reduced. Simultaneously, this helped to instil a sense of confidence among patients and their caregivers. When they observed the positive results of their taking charge of their own health, their concept of self-efficacy was improved.
Reproductive health problems are associated with a sense of shame in Indian setting. Likewise, menopausal health has been one of the neglected areas in our country. In view of the changing demographics of India, this issue needs attention. Even the health policy of our country does not lay emphasis on the health problems of older women, especially during menopausal period. During menopause, there is a potential for women to derive benefit from proper guidance. This is vital in Indian setting where use of HRT is very low. In any case, HRT adverse effects have been highlighted in recent research. BT through MPBT room approach has immensely helped the women having menopausal symptoms.

Pelvic organ prolapse and UI compromise quality of life of women. UI and POP commonly coexist. Most of the women presenting with POP were also diagnosed with UI, and half of the women presenting with UI, in turn, were found to have some degree of POP. ${ }^{1-4}$ In addition, other disorders of the lower urinary tract, such as voiding dysfunction, in women are frequently associated with POP. Approximately $50 \%$ of parous women have some degree of genital prolapse and 10 to $20 \%$ are symptomatic. It significantly affects the fitness and quality of life of the women, including the performance of daily household chores, particularly in rural India where women adopt squatting posture for most household work. The sexual life of women is also affected due to discomfort in pelvic area.

There are surgical and nonsurgical options for treating prolapse. However, most women do not seek treatment until the prolapse problem becomes severe. The reason for such delay are dependent on low status of women in the family, lack of resources/money, extreme scarcity of female doctors and reluctance of women to talk to male doctors about their gynecological problems. Fear of operation is also deterrent. Most women internalize their suffering as part of their routine life and endure pain and discomfort. Besides the natural fear of surgery, most women are busy with their household chores and treatment keeps getting postponed. As a result, most of the women continue to suffer in silence. For mild cases of prolapse, conservative management is possible. Kegel exercises are recommended to strengthen the pelvic muscles in such cases. ${ }^{6,7,15,16}$

Behavior therapy through pelvic floor exercises easily provides relief to women having POP and UI. ${ }^{10-14,2}$ However, for inexplicable reasons, BT has not received the desired attention of the patients and the doctors. Doctors rely more on operations and medicines for their treatment. There is a definite need to popularize conservative management of these problems so that the suffering women can be relieved without using any medicine or surgery. 
It has been reported that pregnant women, especially primigravida women, often lack knowledge on various aspects of pregnancy, labor, postpartum care, and neonatal care, e.g., diet, rest, precautions, appropriate postures while working during pregnancy, recognition of true labor pains, diet, and hydration during labor, etc. Now, all this has been medicalized. Earlier, during pregnancy, elderly women in joint families used to guide pregnant women about maternity/child care. In every joint family, there used to be many married women living together who shared their experiences and helped each other regarding various aspects of motherhood/ maternity. With the breakdown of joint family system, there is usually no one in the family to guide the women on these issues. Such problems are particularly faced by the women who become pregnant for the first time. The traditional birth attendants (TBA) who used to take care of maternity related issues in families are also vanishing. The role of the family members and TBA has been taken over by the hospital set-up. Nurses and doctors are now expected to tell pregnant women about maternity care which was considered earlier an internal family matter. However, most of the time of nurses/obstetricians is spent in clinical care. Consequently, they have little time to attend to routine day-to-day advisory needs of pregnant women. The situation is particularly more critical in India where because of its population size, hospital is overcrowded. Moreover, in government health care set-up in India, female doctors are scarce and are overworked; they are not able to devote adequate time to individual pregnant women. Consequently, in this set-up, preparedness of most women for safe motherhood leaves much to be desired. ${ }^{21,22}$

So, evidently, general public and the clients of maternal health care services need to be educated about some basic aspects of pregnancy care and related issues. The MPBT approach was helpful in this direction. More than 3000 ANC patients were counselled successfully. For empowerment of the patient, different education strategies were devised in this room to propagate self-care.

Counselling is the backbone of infertility treatment. Previous studies have shown that spontaneous conception was seen eventually in around 30\% cases after appropriate guidance and support. Infertility cases require good counselling as they often requires longterm treatment. Affected couples make repeated visits to hospitals. With overburdened hospitals, doctors can barely manage to listen to the problems of these patients. Every case, especially those with treatment failure, need a leisurely approach to deal with them. This, however, is not possible in crowded OPDs. A total of 150 patients were successfully counselled in this room. Unlike OPG-OPDs, couples were counselled together in MPBT room. Thus, they understood the problem better and expressed their concerns without any hesitation.

Primary dysmenorrhea is estimated to trouble at least 40 to $80 \%$ young women. The consequences of untreated primary dysmenorrhea range from lost work and school hours, reduction in the quality of life to family and personal disruption among adolescent girls. Still, the sufferers do not seek medical treatment for this condition, particularly in rural areas, as they lack knowledge of and experience with effective treatment and they believe that it will simply not help. ${ }^{8}$ Culture of silence, tolerance, shyness, and concept of normality is responsible for this situation. Behavioral therapy and many home level measures can be taken for management of dysmenorrhea. However, these measures have not received the desired attention so far. These remedies are simple to use and practically cost almost nothing. Behavioral interventions, such as exercise, may not only reduce dysmenorrhea, but also eliminate or reduce the need for any medication to control menstrual cramps and other associated symptoms. ${ }^{9}$

Overall, a demand has been generated among the women attending OBG-OPD for this room proving that it has definitely met unfulfilled health needs of women. Subjective responses of patients denote their satisfaction after counselling in MPBT room. Workload of doctors in OBG-OPDs also reduced. After necessary history taking and examination, they refered eligible cases to MPBT room. This approach of demedicalization shifted the control of some part of patient management from the medical (doctor) arena to counsellors (and the patient herself).

In addition, all cases coming to room were given sufficient opportunity and time to discuss their problems and doubts with the counsellors (which they do not get routinely in crowded OBG-OPD) in a hospital like PGIMER.

The concept of 'MPBT/health promotion room for women attending gynecology OPD was also disseminated through a series of workshops/presentations/ lectures in different medical colleges. The concept and our findings/experience related to MPBT room were shared with obstetricians/gynecologists through federation of obstetrics and gynaecological societies of India supported regional and national conferences.

Similar efforts were also made through Indian Medical Association (and other professional medical associations), through its regional and national conferences, for practicing obstetricians/gynecologists. This idea was appreciated in every conference/seminar and won many prizes. So far, results have been shared in around 25 regiona/ national/international conferences.

This MPBT model was also replicated in Military Hospital (MH), Naseerabad, Ajmer, Rajasthan (Fig. 1) and MH Jodhpur, Rajasthan (Fig. 2). Team from MPBT 

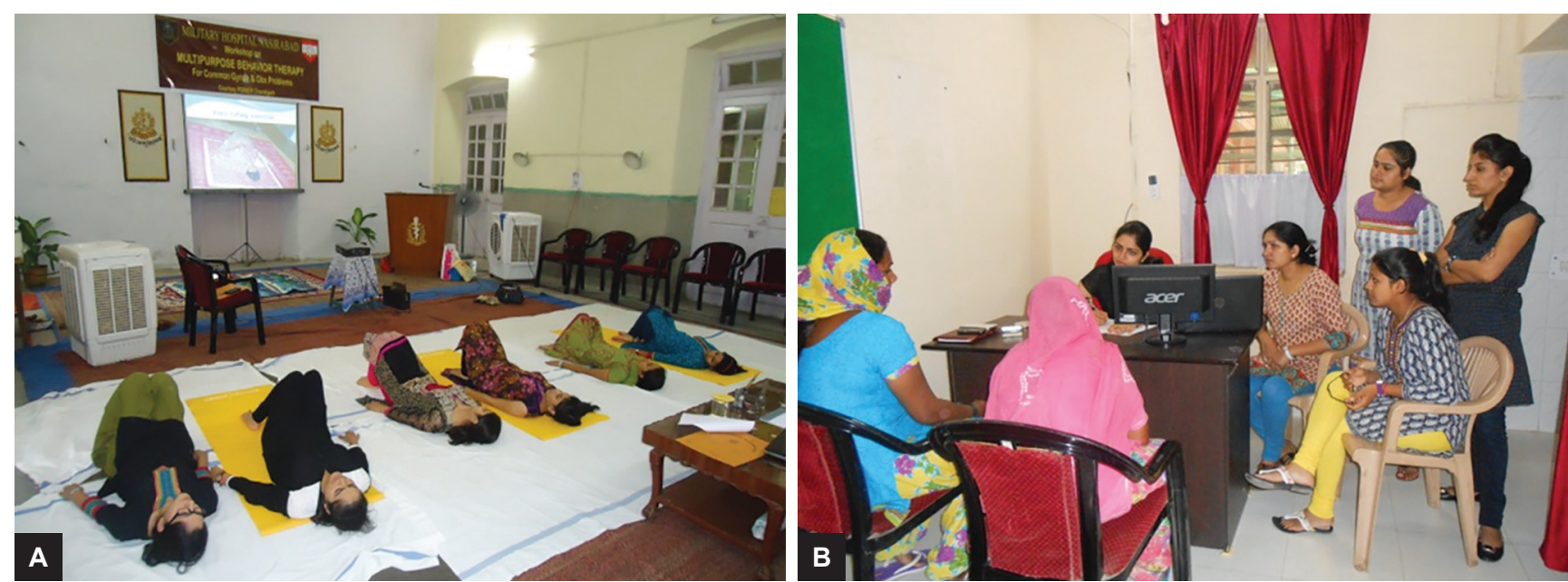

Figs 1A and B: Training sessions and MPBT room replicated at Military Hospital, Nasirabad, Ajmer, Rajasthan
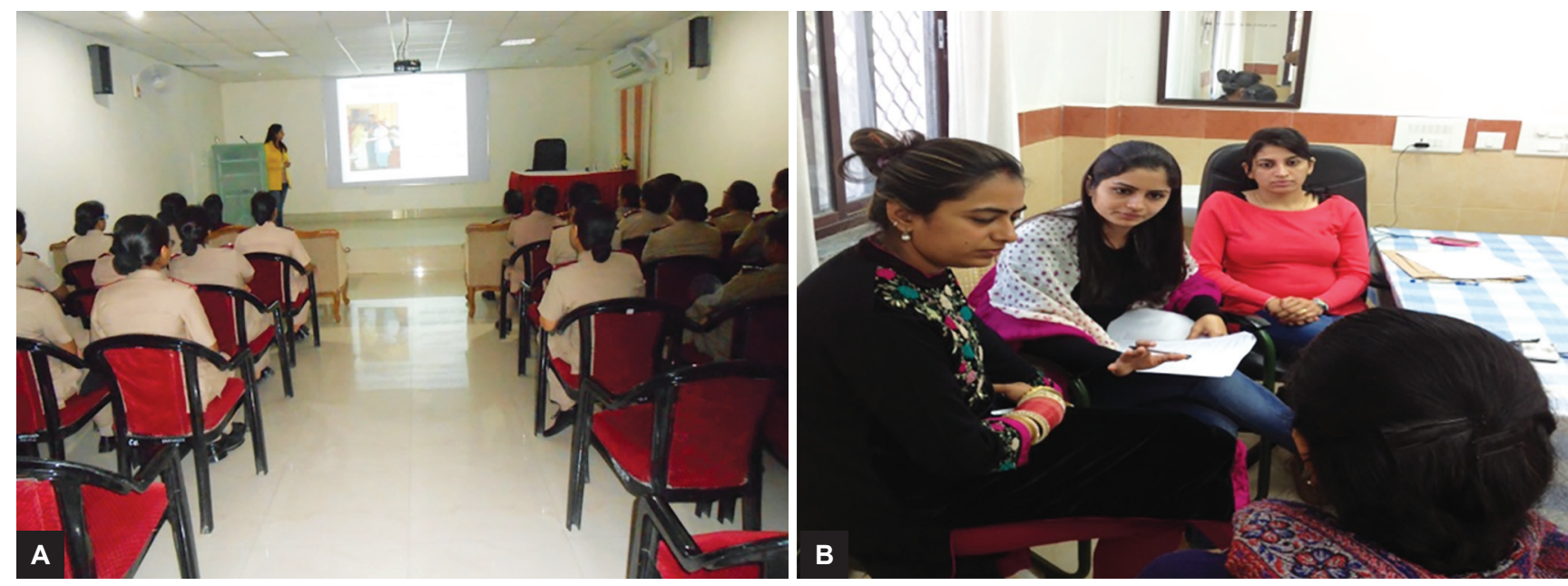

Figs 2A and B: Training sessions and MPBT room at Military Hospital, Jodhpur, Rajasthan

room was invited to $\mathrm{MH}$ and their staff trained regarding approaches used in this room. A similar room was set up there and rooms in both these $\mathrm{MHs}$ have been running successfully till date.

MPBT room ambience and its environment is the first of its kind approach adopted in India. It aimed to make patients comfortable and relaxed so that they could express their problems freely. Popularity of this room grew several fold. This room not only enhanced quality of care provided in hospitals but also led to health awakening among females and instilled a sense of confidence among them. Replication of this model in other medical colleges will also help in reducing the load on doctor while simultaneously enhancing patient satisfaction.

\section{CONCLUSION}

A Department of Bio technology sponsored MPBT room ws set up in OPG-OPD in PGIMER, Chandigarh in December 2012. Patients from main OPD were referred to this room where the research team provided counselling.
Approximately 5000 patients were counselled in this room. Patients of infertility, prolapse, UI, menopause, PCOD, and dysmenorrhoea were advised nonmedicinal interventions, i.e., appropriateBT, health education, lifestyle changes, dietary change, bladder training, Kegel exercises, and genital hygiene. Antenatal patients were successfuly counselled regarding care during pregnancy, mild exercises, and healthy diet. Therefore, establishing a counseling room/MPBT room in hospital OPDs has a potential to help women cope better with the issues related to their fitness and health.

\section{REFERENCES}

1. Bump RC, Norton PA. Epidemiology and natural history of pelvic floor dysfunction. Obstet Gynaecol Clin North America 1998 Dec;25(4):723-740.

2. Brown JS. Epidemiology and changing demographics of overactive bladder: a focus on the postmenopausal women. Geriatrics 2002 May;57 (Suppl 1):6-12.

3. Peyrat L, Haillot O, Bruyere F, Boutin JM, Bertrand P, Lanson Y. Prevalence and risk factors of urinary incontinence in young and middle-aged women. BJU Int 2002;89:61-66. 
4. Hampel C, Wienhol D, Banken N, Eggersmann C, Thüroff JW. Prevalence and natural history of female incontinence. Eur Urol 1997;32 (Suppl 2):3-12.

5. Rana A, Suri V, Walia I, Singh AJ. Pregnancy cures for common illness and neonatal care. Century Publications, 2008.

6. Sharma R, Kashyap R, Kaushal P, Jain V, Singh AJ “Bacchedani Bahar Ana-Prolapse Uterus" New Era International imprints vide ISBN No-978-81-290-0067(Hindi).

7. Sharma R, Kashyap R, Kaushal P, Jain V, Singh AJ “Bacchedani Bahar Ana-Prolapse Uterus". New Era International imprints. ISBN No-978-81-290-0068-2 (Punjabi).

8. Chaudhary A, Singh AJ, Dhaliwal L. A simple solution to painful mense. New Delhi,Century Publications, 2011.

9. Sharma R, Chaudhary A, Kaushal P, Jain V, Singh AJ. "Mahawari da dard- Bachaav Atey Elaaj". New Era International imprints. ISBN No-978-81-290-0075-0 (Punjabi).

10. Kumari S, Jain V, Mandal AK, Singh A. Behavioral therapy for urinary incontinence in India. Int J Gynaecol Obstet 2008 Nov;103(2):125-130.

11. Kumari S, Jain V, Mandal AK, Singh AJ. Auratan wich Peshab Leek Hon di takleef da Aasan Ilaj, New Delhi, Century Publications, 2011(Panjabi)

12. Kumari S, Meenakshi, Jain V, Mandal AK, Singh AJ. Behavior therapy for urine leakage in women-from research to practice. New Delhi, Century Publications, 2011.

13. Kashyap R, Singh AJ, Jain V. Conservative management of pelvic organ prolapse. New Delhi,Century Publications, 2011.

14. Kashyap R, Singh AJ, Jain V. Auraton main bachchadani bahar aane ki bimari ka bina operation ilaz. New Delhi,Century Publications, 2011.
15. Sharma R, Kumari S, Kaushal P, Jain V, Mandal AK, Singh AJ. "Mahilaon mein peshab leakage" (Urinary Incontinence). New Era International imprints. ISBN No-978-81-290-0074-3 (Hindi).

16. Sharma R, Kumari S, Kaushal P, Jain V, Mandal AK, Singh AJ. "Mahilaon mein peshab leakage" (Urinary Incontinence). New Era International imprints. ISBN No- 978-81-290-0080-4 (Punjabi).

17. Singh AJ. Promoting Health Through Hospitals (Chapter-19). In Hospital Administration and Management - Theory and Practice. S.L Goel and R. Kumar (Eds). New Delhi. Deep and Deep Publication Pvt. Ltd 2007; 387-426.

18. Kaushal P, Sharma R, Aggarwal N, Chopra S, Singh AJ "Menopause- A new approach to deal with menopause related problems" New Era International imprints. ISBN No-978-81290-0070-5 (English).

19. Kaushal P, Sharma R, Aggarwal N, Chopra S, Singh AJ . "Rajoneevriti-Menopause se sambhandhit samasyaon k samadhan ka ek naya drishtikon" New Era International imprints vide ISBN No-978-81-290-0081-1(Hindi).

20. Kaushal P, Sharma R, Aggarwal N, Chopra S, Singh AJ "Rajoneevriti-Menopause se sambhandhit samasyaon $\mathrm{k}$ samadhan ka ek naya drishtikon". New Era International imprints vide ISBN No-978-81-290-0083-5 (Punjabi)

21. Neha, Sharma R, Rana AK., Suri V, Singh AJ, Kaushal P. “ Garbhavstha se sambandhit shankayan va unka samadhan". New Era International imprints vide ISBN No-978-81-2900121-4 (Hindi).

22. Demedicalizing Women's Health. AJ Singh (Editor), (Mrs.) Indrajit Walia, LK Dhaliwal (Co-editors), New Delhi, Gyan Publishing House, 2010. 